A multidisciplinary approach to the mutual shaping process in electronic identities

or

"We shape the tools and thereafter they shape us" McLuhan

\author{
Ana Viseu \\ December 17,1999
}




\section{Generically speaking}

New forms of communication allow for new modes of expression of identity. Consequently, the appearance of new digital technologies creates new forms of identity. In Western cultures the belief that new technologies are a sign of progress and enclose the hope for a better world is deeply ingrained (Mumford, 1970; Noble, 1997). Consequently, electronic identity also encloses the promise of re-birth and freedom from outdated social conventions.

Electronic identity, many believe, provides the best opportunity to express who we really are or, in case this is not what we want, who we really would like to be. The social spaces created by computer networks, most commonly known as cyberspace, offer the promise of an environment free of stereotypes, social conventions, and physical constraints, such as age, gender, or race. The new Self is said to be multiple, distributed and fluid, and most of all it is said to be a representation of its proprietor 's will (Turkle, 1995; Stone, 1996).

While it is accurate to say that new forms of communication allow for new modes of identity expression, it is, to say the least, problematic to assume that this relation is unconstrained or dictated by only one of the actors involved. Rather, it is negotiated by the totality of social actors involved, i.e., digital networks and its users, or on a larger level, technology and society.

The assumption that technology is an objectifiable variable that can be isolated and worked on, is pervasive. And so is the belief that we can act directly upon it. But the relation between both entities is not this clear or unidirectional. As Manuel Castells puts it, "technology does not determine society: it embodies it. But neither does society determine technological development: it uses it.... [There is a] dialectical interaction between society and technology" (Castells, 1996, p. 5). Hence, technology and society interact and mutually shape each other; the same is true for new forms of identity and new technologies of communication.

Put in plain words, this relationship is expressed the following sentence: "we shape the tools and thereafter they shape us" (McLuhan, 1964). The relationship between us and our tools is not unidirectional. Neither can we ascribe the sense of agency exclusively to humans, nor can we classify this relationship as one of purely dictated by technological determinism. Rather, this relationship is one of mutual adaptation through constant feedback. 
The perspective of mutual shaping of social actors and technology is one what I want to adapt in my future research on electronic identities.

\section{Methodologically speaking}

As we enter the Information age, an age of ubiquitous computational technology, the boundaries between both society and technology blur ever more, and their boundaries overlap to the extent that they can no longer be separated. "Looking at society, one finds that technology plays a role in almost all of its aspects. By investigating technology one finds the social arrangements, those which it embodies and those in which it is applied" (Stalder, 1997). Therefore, I propose to start by researching the relationship of mutual shaping between technology and society, focusing specifically on its importance to the creation of new identity forms.

The subject matter of electronic identity is made up of a combination of different elements that derive from various fields. In order to investigate it, it is necessary to adopt a multidisciplinary approach. The perspective of mutual shaping is a useful conceptual tool for this type of research, and has been recently adopted in a variety of social and human sciences.

Accordingly, when looking at the construction of identity in electronic media these are the various fields I will draw upon: Cultural psychology; communication theory (media and cultural studies); social and technological constructivism; sociology and finally, computer science. The distinction between these fields is, many times, subjective and arises from the need to categorize in order to clarify. Many of these fields deal with similar issues and overlap in important points.

\section{An overview of the different disciplines}

\section{Cultural psychology}

The field of cultural psychology "only recently... emerged as a commonly acknowledged field of scientific research" (Baerveldt, 1996). Cultural psychology is a multidisciplinary discipline as it shares many of its concerns with sociology, cultural studies, anthropology and psychology. It is rooted in the works of philosophers such as Wundt, who defended, in the early twenthiest century, the idea of a Voelkerpsychologie ("spirit of the people"). Wundt argued that this second psychology cannot be studied in laboratory because it extends beyond human consciousness; and 
psychologists such as Vygotsky and Luria, who advocate that the mind is social. The works of Jerome Bruner and Michael Cole are commonly regarded as the best entry point to the growing field of cultural psychology.

Cultural psychologists advocate that culture and mind are intertwined, and that the artificial division between mind and culture is rooted in the modern science paradigm of experimentation. The doctrine of scientific knowledge led to the separation between natural sciences and humanities, and to the later division between social sciences and humanities. Culture, they say, is constitutive of mind and mind emerges from culture.

The cultural psychology approach to mind, culture and their interaction can be summarized as follows: "[S]ociocultural settings shape mental functioning... through the cultural tools [or artifacts] employed" (Cole, 1996, p. 333). Likewise, artifacts are a product of the action of the human mind. Already here can we identify a mutual shaping relation, a relation well characterized in the following statement:

[N]o sociocultural environment exists or has identity independent of the way human beings seize meanings and resources from it, while every human being has her or his subjectivity and mental life altered through the process of seizing meanings and resources from some sociocultural environment and using them (Shweder, 1984, p. 2; quoted in Cole, 1996, p. 103)

For cultural psychology, culture is a medium composed of artifacts that the social group has accumulated. "An artifact is an aspect of the material world that has been modified over the history of its incorporation into goal-directed human action" (Cole, 1996, p. 117). These artifacts have a dual nature, they are simultaneously conceptual and material: they are conceptual because they participate in the process of their own shaping and because they are manufactured for a reason, they become material when put to use. Cultural psychology focuses on the feedback, the interaction, between the conceptual and the material. The constraints of the material will undoubtedly stifle the conceptual, likewise the conceptual possibilities are engraved on the material. 
Culture, according to this perspective is conceptual and material, internal and external. And so is the mind:

What we call mind works through artifacts, it cannot be unconditionally bounded by the head or even by the body, but must be seen as distributed in the artifacts which are woven together and which weave together individual human actions in concert with and as part of the permeable, changing, events of life (Cole, 1996, pp. 136-137)

In his book Cultural psychology Cole exemplifies the duality of the mind with the example of a blind man using a stick to walk down a road. Cole points out that in this example it is very hard to determine where the man ends and the stick starts? Where does the mental system finish, at the handle of the stick? Or, giving a more current example, when we are in cyberspace where does our 'self' start and finish? This idea of artifacts as 'proesthetics' of the human body and mind is an idea also utilized in the field of media theory.

\section{Communication Theory (medi a and cultural studies)}

The idea of tools as 'proesthetics' of the human body and mind, resonates with those of Marshall McLuhan (McLuhan, 1964; see also Bowers, 1993) who studied the intersection between media and culture. McLuhan argued that media are extensions of man: The pen is an extension of the hand, the wheel an extension of the leg, the alphabet - Luria's 'tool of tools' - an extension of the mind. In his article "Childhood and the cultural amplification characteristics of computers: Some critical concerns", Bowers also makes a similar argument. He asserts that all technologies amplify and reduce certain aspects of knowing and perception. He quotes Idhe's example of "a person who manipulates a stick in order to reach fruit located in the top branches. The technology extends (amplifies) the reach of the person but reduces those aspects of experience relating to touch and smell - which may be important to determining whether the fruit is ripe" (Ihde, 1979, p. 53; quoted in Bowers, 1993, pp. 37-38). Bowers also makes the connection between technology and culture by saying that on the one hand culture is a blueprint for making sense out of the world, and on the other, technology is a constitutive part of Western cultural discourse. Therefore, he argues, technology is not merely a tool it has a great role "on the formation of consciousness (both in terms of explicit and taken-for-granted patterns of understanding) and self-image" (Bowers, 1993, p. 37). 
McLuhan also made the argument that technology is not merely a tool. He argued that technology is not neutral, and exemplified it with several illustrations. The introduction of a new technology alters the ratio of the senses (McLuhan, 1962), e.g., the proliferation of print resulted in a change from an oral culture to a visual culture. Print also gave rise to other social phenomena such as the nation-state, of national languages and individualism. McLuhan's "the medium is the message" (McLuhan, 1964) is another example of the non-neutrality of the technology, for it means that the content transmitted is profoundly shaped/molded by the medium in which it is transmitted. A medium is more than what we do with it. It shapes the message itself. The idea of the nonneutrality of the media was pioneered by Harold Innis in the books Empire and communications (1950) and The bias of communication (1951).

Technology is not neutral and its biases translate into a relationship of mutual shaping, i.e., technology is simultaneously a product of man's action, and a cause of man's change. But neither action is direct, predictable or self-conscious. When discussing the unintended consequences of technology, Jacques Ellul gives the example of the developments being made in the field of pesticides. He says that these have resulted in bigger and better crops, nonetheless, they also increased the pollution level (Ellul, 1981, p. 68). Another example is the automobile. The appearance of the automobile shortened distances. But, on the other hand, the pollution levels rose and, as Lewis Mumford puts it "in America, man has begun to lose the use of his legs, as a result of over-dependence upon the car" (Mumford, 1972, p. 134).

\section{Sociology}

In the book Discipline and punish: The birth of the prison, Foucault (1975) advances the idea of identity as discourse, of the 'legible' body. Foucault argues that this 'legible' body is subject to the imposition of different 'tags' that shape not only the individual's perception of his/her own identity, but also how they are perceived by others. Foucault highlights the power that different labels, such as "criminal" or "insane", have in determining someone's identity; and also the enormous power of the institution that awards these labels. 
The same type of argument is made by Clarke, who focuses on electronic identity, and specifically of digital persondt. Clarke points out the distinction between 'projected' and 'imposed', and 'formal' and 'informal' identities. He specifies that a projected identity is, at least partially, controlled by the individual, an imposed identity, however, is established by others. According to Clarke informal identities are based on human perceptions, while the formal identities are based on the accumulation of structured data. Most of the research that is being done on electronic identities focuses on the 'projected' type --- graphical or textual. But the notion of imposed or projected identities is of great relevance because of the characteristics of the medium itself. Digital networks are environments that are made up of data accumulation. Therefore, a digital persona, or electronic identity, is itself a data cluster. This being said several questions that arise: who labels this cyb-id? Who decides which data will be accumulated and to what end? Who has access to it? As computers become ubiquitous, electronic monitoring devices pervasive, and virtual life a part of everyday's life the question of imposed identities is one of great importance.

Two of the most important figures in the exploration of electronic identities are Sherry Turkle and Rosanne Stone. Both authors focus on projected identities, in the context of role playing activities: Graphical or textual MUD's (Multi User Dungeons) and chat lines. In the book Life on the screen: Identity in the age of the internet, Turkle states that the computer is not merely a tool, or even an information carrier, it is an actor with whom the user interacts or, as Stone puts it, it is an "arena for social experimentation" (Stone,1996). Turkle then declares that "the computer offers us new models of mind and a new medium on which to project our ideals and fantasies" (Turkle, 1995, p. 9). Turkle draws an analogy between the computer's windows, and the creation of a new multiple, distributed self as an example of the effect of the continued relationship with technology.

\section{Social and Technological Constructivism}

In an article entitled "Constructivist, interpretivist approaches to human inquiry" Schwandt outlines the history and development of the constructivist movement. Constructivist proponents, says Schwandt, fight against the notions of objectivism, empirical realism, objective truth and essentialism" (Schwandt, 1994, p. 125). Constructivists argue that reality is both pluralistic and plastic. Pluralistic because it can be expressed in a variety of representation systems, and plastic

\footnotetext{
${ }^{1}$ A digital persona is "is a model of an individual established through the collection, storage and analysis of data about that person" (Clarke, 1994).
} 
because it can be stretched to fit actions of human agents. Consequently, in a constructivist perspective to understand the "complex world of lived experience [it is necessary to do it] from the point of view of those who live it.... [Moreover, constructivists argue that] [t]he world of lived reality and situation-specific meanings that constitute the general object of investigation is... constructed by social actors" (Ibid, pp. 118-119). It follows that in a constructivist approach "[s]ocial agents are considered autonomous, intentional, active, goal directed; they construe, construct, and interpret their own behavior and that of their fellow agents" (Ibid, p. 120).

In The social construction of reality, Berger and Luckmann lay the foundations of social constructivism? The authors argue that everyday reality is socially constructed, and that in order to 'hold together' it is possesses several levels of legitimation, i.e., processes of "justiffying] the institutional order by giving a normative dignity to its practical imperatives" (Berger \& Luckmann, 1966, p. 86). The fourth and most comprehensive of these processes of legitimation is that of 'symbolic processes'. "[A] symbolic universe is conceived of as the matrix of all socially objectivated and subjectively real meanings" (Ibid, p. 89). The media with their role of 'symbolic industries' play an important role in the legitimation of social reality, that is, in the shaping of the every day life reality. The media are, therefore, seen as social agents that actively participate in the negotiation and legitimation of 'society'.

On the theme of identity Berger and Luckmann argue "[i]dentity is a phenomenon that emerges from the dialectic between individual and society. Identity types, on the other hand, are social products tout court, relatively stable elements of objective social reality" (Ibid, p. 160). Therefore, the authors declare that in order to study identity it is essential to contextualize it within a theoretical framework. For example, "a psychology interpreting certain empirical phenomena as possession by demonical beings has as its matrix a mythological theory of the cosmos, and it is inappropriate to interpret it in a non-mythological framework" (Ibid, p. 160). Hence, when studying electronic identity one must keep two things in mind: that technology itself is a social actor, therefore bounded by the dialectical nature of the construction of social reality. And that electronic

\footnotetext{
2 Social constructionism is based on the assumption that "[t]he terms by which the world is understood are social artifacts, products of historically situated interchanges among people" (Gergen, 1985, p. 267; quoted in Schwandt, 1994, p. 127).
} 
identity must be studied in the context of digital technologies, for example, through the analysis personal of web sites, or electronic consumer profiling databases.

Other scholars, such as Bijker, Winner, Law and Callon, have focused on the thematic of technological constructivism, or science, technology and society studies. According to these authors "the social is materially heterogenous" (Callon \& Law, 1997) and this implies that it is not only made up of bodies, but also technologies, texts, money, and buildings. Non-human materials are social actors and should not be thought of as mere resources or constraints that are only active when used by flesh and blood actors. These scholars insist on the fact that non-human materials play an important role in the making of reality. This implies that any significant account of the development of a social process, such as the formation of electronic identities, must take into consideration not only the human actor, but also the technology itself.

\section{Concl uding}

The starting point for this proposal is that new forms of communication create new forms of expression of identity, more precisely new digital technologies create possibilities for new electronic identities. However, this is not a causal relationship, or a unidirectional action. Rather, it is the result of a mutual shaping relation, where both the technology and the human actors influence one another. To investigate the dynamics of this interaction it is necessary to engage in multidisciplinary research:

Constructivism/science studies emphasize that media are social actors, who participate actively in the social construction of everyday reality. As any other social actor, technology possesses the power to act and shape (and of course, be shaped). Therefore, in order to study the emergence of new artifacts, it is necessary to focus on the relationship between social actors, not on their essence.

Communication theory adds that the media, and technology in general, are not neutral. Technology has its internal biases and not only affects the message it conveys, but also the Self. Media amplify certain senses and act as a blue print for social practices, much in the way culture does. 
Cultural psychology states that sociocultural settings shape the mind through the artifacts employed. The mind is distributed in the artifacts, and it interacts with them in order to make 'sense' out of everday's reality. Therefore, the artifacts themselves are active in the process of shaping both the realities of the culture and the self.

Sociology highlights the difference between two types of online identity — projected and imposed. This discipline shows some of the dynamics of 'real life' identity that are at play in the electronic environments.

Each of the above mentioned disciplines emphasizes distinct aspects of online identity, while still agreeing that their creation is based on a process of mutual shaping and negotiation. Another commonality is the interest in investigating the emergence of new forms of expression of identity.

As more of our everyday life is spent in online environments the need to research the dynamics of identity representation in these environments increases. Currently most of the research focuses on the issue of projected informal identity in the context interpersonal communication, that is, chat rooms, MUDs (graphical or textual), and activities that involve role-playing. However, there are other types of electronic identity being developed daily, such as projected formal identities personal websites - and imposed identities - of which a good example is the pervasiveness of cookies on the internet. The next step in my research agenda is to simultaneously develop the concepts outlined in this synopsis and to investigate their specific applications, in order to find concrete examples in which more empirical research can be carried out. 
References

Baerveldt, C. (1996). Manifesto for a cultural psychology. [Online]. Available: http://www.socsci.kun.nl/psy/cultuur/manifesto.htm [1999, Nov. 19].

Berger, P. \& Luckmann, T. [1966] (1980). The social construction of reality: A treatise in the sociology of knowledge. New York: Irvington Publishers, Inc.

Bowers, C. A. (1993, June). Childhood and the cultural amplification characteristics of computers: Some critical concerns. Holistic Education, 6, 2, 35-44.

Callon, M. \& Law, J. (1997). After the individual in society: Lessons on collectivity from science, technology and society. Canadian Journal of Sociology, 22, 2, 165-182.

Castells, M. (1996). The rise of the network society. Massachusetts, USA: Blackwell.

Clarke, R. (1994, June). 'The digital persona and its application to data surveillance. The Information Society, 10, 2 [Online]. Available: http://www.anu.edu.au/people/Roger.Clarke/DV/DigPersona.html [1999, Nov. 9].

Cole, M. (1996). Cultural psychology: A once and future discipline. Cambridge, MA: The Belknap Press of Harvard University Press.

Ellul, J. (Vanderburg, W., Ed.) (1981). Perspectives on our age: Jacques Ellul speaks on his life and work..(translated by Joachim Neugroschel). New York: The Seabury Press.

Foucault, M. [1975] (1995). Discipline and punish: The birth of the prison. (translated by Alan Sheridan). New York: Vintage Books.

Gergen, K. J. (1985). The social constructionist movement in modern psychology. American Psychologist, 40, 266-275.

Idhe, D. (1979). Technics and Praxis. Dordrecht, Holland: Reidel.

Innis, H. (1950). Empire and communications. Oxford: Clarendon.

- - - - - (1951). The bias of communication. Toronto: University of Toronto Press.

McLuhan, M. (1962). The gutenberg galaxy. Toronto: University of Toronto Press.

- - - - - [1964] (1994). Understanding media: the extensions of man. Cambridge, Massachusetts: MIT Press.

Mumford, L. (1970). The myth of the machine: The pentagon of power. New York: Harcourt Brace Jovanovich, Inc.

- - - - - [1972] (1978). The transformations of man. Gloucester, MA: Peter Smith. 
Noble, D. F. (1997). The religion of technology. New York: Alfred A. Knopf.

Schwandt, T. A. (1994). Constructivist, interpretivist approaches to human inquiry). In Denzin, N. K. \& Lincoln, Y. S . (Eds.). Handbook of qualitative research (pp. 118-137). Thousand Oaks, CA: Sage Publications.

Shweder, R. A. (1984). Preview: A colloquy of culture theorists. In R. A. Shweder \& Levine, R. A. (Eds.). Culture theory: Essays on mind, self and emotion. New York: Cambridge University Press.

Stalder, F. (1997, Dec.). What does technology do? [Online]. Available: http://www.fis.utoronto.ca/ stalder/html/technology.html [1999, Dec. 01].

Stone, R. [1996] (1998). The war of desire and technology. Cambridge, MA: MIT Press.

Turkle, S. (1995). Life on the screen: identity in the age of the internet. New York: Touchstone 